\title{
On the Course Reform Construction of Network Teaching Mode of Contract Law
}

\author{
Hang Liu \\ Nanchang Institute of Science \&Technology, Nanchang 330108, China
}

Keywords: curriculum; educational reform; teaching mode

\begin{abstract}
In the 21st century, with the development of Network information technology, the Network course of our country has also been carried out. Based on courses of Network education, the technology reform of our country makes use of Network technology and takes practice of the teaching reform, forming the teaching quality and mode of courses. Here, it is necessary to stress to take Internet as the guidance and emphasize the course of "Contract Law" where teachers and students transmit information to self-study.
\end{abstract}

\section{Introduction}

Now we take good teaching resources as the platform, apply all high-quality teaching factors, make teaching more comprehensive, and integrate learning and research. So in view of the role of the derived three-dimensional research teaching mode in the teaching reform of Contract Law, practice is the action.

\section{Key of Teaching Mode}

Now the Network education technology is a brand-new mode. According to modern educational thoughts, research on modern is directed at teaching and education mode while practicing and studying, so as to cultivate students' learning ability, autonomous learning ability, autonomous learning enthusiasm and arouse their interest in learning. Besides, we need to design teaching according to the concepts of Internet education and teaching, explore innovative consciousness and ability in curriculum teaching materials, teaching method and form of discussion. In addition, we should have more in-depth researches on corresponding subjects, accumulate types of knowledge homework, innovate training methods. All those concerned will constitute an overall three-dimensional research mode, form a comprehensive system, realize the process of stereoscopic research, expand students' horizons, and develop their potential. It is the teaching reform of the development of education in China, and we must take the first step.

In the 21st century, modern teaching resources are an open platform system. In the process of teaching, we should do our best to collect all kinds of resources, so as to realize the modernization and three-dimensional feature of modern teaching. In the teaching process of Contract Law, some authors try their best to make full use of and integrate the resources of multimedia and self-media, apply modern teaching Network means, use and manufacture multimedia and self-media teaching courseware or software which take knowledge imparting as the main function and concentrate on self-study function and so on. In addition, we can also optimize the Network teaching environment, realize teaching dynamic autonomy, and extend classroom teaching to Network self-media platform. In the online classroom, we open students' electronic reading room, course information appraisal, question collection, questions answering by teachers, conversations between teachers and students, recording and broadcast playback of teaching resources and so on, all of which can provide column activities such as electronic teaching materials and question answering on the Network, discussions between teachers and students and so on. Thus, we will form a way of interaction and communication in and outside classes, mobilize the enthusiasm of students to learn independently and offer consults for students when they encounter practical problems during self-study. 


\section{Practice of Three-dimensional Mode of Contract Law Teaching}

In legal system, Contract Law is the backbone of majors, and it is a theoretical and practical teaching course, occupying an important position. Most people always want to explore practice of research types, through the process of practice, to achieve a three-dimensional process of teaching, including teaching contents, methods, resources and other important elements. We need to establish the concepts of research teaching, which is the premise of teaching mode and the core of research teaching is to study the process of teaching. The combination of these two practices will play a guiding role in students' thinking, research and exploration. This is reflected in respectively students' main body function and participation. The guidance enhance their interest in learning, cultivate their learning ability, and help them to learn to find problems, put forward problems, so as to solve problems in the process of learning. During self-love analysis and problem-solving, students will develop the ability of research, carry forward the positive spirits of learning science, carry out three-dimensional research teaching mode and establish a firm teaching idea. We must put this kind of "research" teaching ideas into teaching curriculum.

Contract Law plays the role of using educational resources for three-dimensional exploration in the educational system. Based on the construction of resources, through an open platform, we should do our utmost to search for all resources to be integrated in the teaching process, so as to gather teaching as the main body and adopt modern education means. Through practical actions, we can explore the implementation process of a three-dimensional and comprehensive research-oriented teaching, which refers to some important factors, such as the need of three-dimensional and all-round standardization of teaching, the use of teaching resources, teaching steps and so on.

First of all, we have to establish a research-oriented teaching concept. We should integrate research concepts into teaching process so as to realize the combination of these two. The term of "research-oriented" is reflected in students' main role of themselves. In the improvement of "participation", we offer guidance to students in the process of thinking, research, and exploration. This can enhance students' interest in learning, which will not only broaden their own professional horizons, but also develop their own abilities to do scientific research and exploration, so that students can learn to discover, propose, analyze and solve new problems while learning new knowledge. In order to carry out the three-dimensional research teaching mode, we must establish the concepts of "research-oriented" teaching, and fully implement these concepts in all teaching elements of the course. We need to carry out the research teaching idea thoroughly and apply teaching design ideas of "research-oriented" to the whole process of teaching and learning. Now we should conform to the construction of research teaching resources to explore the three-dimensional and all-round teaching mode, among which the most basic tool is to construct research teaching resources.

It is necessary to construct a system of curriculum contents, consisting of three lines: theoretical courses, practice courses and scientific research training. The whole system of theoretical courses is made up of course units. Therefore, we should know that teaching of imparting type in a reasonable teaching mode pays more attention to the accuracy and solidity of knowledge, as well as the general acceptance and bearing ability of knowledge. In the teaching mode, we should stress the pioneering nature of knowledge and the grasp of present situation, focusing on developing students' general application ability and the ability to find and solve problems independently. However, due to the limitations of materials and teaching, courses offered by universities and colleges often have a certain gap between the development of teaching and subjects. Therefore, in the construction of course contents of Contract Law, we should achieve "three combinations" so as to highlight the pertinence, and thus form a set of suitable system for the society and the cultivation of professional talents in our college. Practical courses inside and outside colleges emphasize that through practical training, we can enhance students' innovative consciousness and their comprehensive abilities.

We not only have realized the advanced practical teaching environment in the teaching of Contract Law, but also have changed from a single college classroom teaching to a combination teaching of small college classroom and a large social classroom. There are teaching bases in 
companies, and mock courts in colleges, in which students can practice, develop their own application ability and learn to accept the training of academic research and the edification of academic atmosphere, playing a role in guiding students into the field of academic research as soon as possible. In ordinary teaching, we encourage students to actively participate in tasks assigned by teachers. It can not only train students' practical ability, comprehensive ability of solving problems and the basic literacy of scientific research institute. For teachers, students' endless questions will bring unexpected inspiration and creative inspiration, so that teachers will achieve jump thinking. This kind of scientific research will be full of dynamic power.

Teaching contents of knowledge imparting and research type are the important mediums of this three-dimensional and research-based teaching mode, which is the content of research-oriented curriculum, so it should emphasize thinking ability and practical ability, and the cultivation of creative ability. In view of the reform of the Contract Law, we should pay great attention to the optimization and integration of knowledge among various disciplines. We all advocate that students should be able to think independently of the so-called hot and difficult issues that they are concerned about as well as correctly guide them to carry out effective theoretical research and exploration on their own. The contents taught by teachers emphasize key points, difficulties and doubts. In this way, if teacher teaches a few but fine contents, we will have enough study time and thinking space for students to do self-study exploration and research, successfully guide them to understand from multiple angles and deep levels.

The core of implementing this three-dimensional and research-oriented teaching mode is to adopt the research-oriented education method. According to the teaching strategy, we take students as the main body around the teaching process of Contract Law, adopt multiform and all-sided interactive communication teaching, pay special attention to situational approach and add a lot of interesting contents. At the same time, it also attracts students' attention and thinking, so that students can participate to interact and explore. This can fully mobilize the initiative of students to learn, improving the quality of teaching and results. It is also a diversified comprehensive system in the examination process of Contract Law teaching mode. All aspects of assessment methods are centered on the ability cultivation, enhancing students' ability of assessment gradually. In this way, students can learn a lot from learning new knowledge in textbooks and reading books of interest. What is more important is to explore the subject through self-thinking. This is the enthusiasm that really inspires students' learning potential, arouses their desire of independent innovation, and promotes their creative thinking.

\section{Probe into the Implementation of Teaching Mode}

The biggest advantage of research-oriented teaching mode is to help students to learn independently and improve their own enthusiasm. Teachers play a leading role in the teaching process, so in the corresponding teaching mode, teachers are required more for their education and scientific research abilities. For the contents of courses taught by teachers and comprehensive problems will translate the latest scientific research results into optimized teaching resources. Meanwhile, students are instructed to carry out various literature surveys and some appropriate scientific researches, etc. Only in this way, teachers can fully incorporate the enthusiasm of innovation into course teaching, and they may be able to create a harmonious atmosphere of learning and innovative thinking. Therefore, we must have a teaching and research team of teachers and subjects strength in order to support the research-oriented teaching mode. Besides, only teachers' deep academic foundation can support the high quality of teaching. The reform of teaching management mode and teaching operation mechanism also have a certain influence on the research-oriented teaching mode, therefore, the flexibility of teaching operation mechanism is required more.

\section{Conclusion}

In the future, how to reasonably evaluate the input and teaching effects of teachers and how to 
effectively establish incentives for teachers to carry out the research teaching are problems worthy of our further exploration and research. Only by making students experience equality, democracy, respect, understanding and love, fell encouraged, inspired, and instructing, can they form a positive life attitude and give full play to their ability of self-determination and creativity.

\section{References}

[1] Wang Yueping. Research on the Network Course Reform of Law Major Based on Moodle: A Case Study of Contract Law [J]. Journal of the Open University of Guangdong, 2015, 2405: 10-13.

[2] Jiang Guijin. On the Three-dimensional Research-oriented Teaching of Contract Law [J]. Journal of Liaoning Educational Administration Institute, 2008, 04: 63-64.

[3] Xin Hong. The Application of Multimedia Technology in Higher Law Teaching: The Design of Contract Law Learning Website [J]. Heilongjiang Researches on Higher Education, 2006, 06: 127-128.

[4] Jin Ying. The Construction Principles and Reform Contents of the Teaching Mode of Open Education [J]. Journal of Radio \& TV University (Philosophy \& Social Sciences), 2004, 04: 121-123.

[5] Zhuang Honglei. A Probe into the Teaching Mode of the Course of Economic Law in Higher Vocational Education [J]. Journal of Lianyungang Technical College, 2014, 2701: 71-73+ 89.

[6] Cao Yan. The Construction of Practical Teaching System of the Economic Law Course for the Applied Undergraduate Economic Management Major [J]. China Economist, 2013, 01: 128-130. 